\title{
Religiusitas dan Entrepreneurship
}

\author{
Muhammad Shohib ${ }^{1}$ \\ Fakultas Psikologi, Universitas Muhammadiyah Malang \\ Progtram Studi Doktor Psikologi Fakultas Psikologi Universitas Airlangga \\ e-mail:m.shohib.umm@gmail.com
}

\begin{abstract}
Entrepreneurship has contributed considerably in the country's economic growth, so research on this theme is increasingly in demand and growing well. Religiosity has given a distinctness in the individual and influenced his behavior. This study aims to examine the relationship of religiosity with entrepreneurship by using literature review. Literature review search was cunducted on ProQuest, EBSCO, Science Direct electronic database using keywords of entrepreneurship and religiousity. We found that religiosity has a strong association with entrepreneurial behaviors and traits, both as a distinctive feature of entrepreneurial character that distinguishes between high and low religiosity, strategy in entrepreneurship and other psychological aspects of entrepreneurship.
\end{abstract}

KEYWORDS Entrepreneurship, religiousitas

CITATION Shohib, M. (2018). Religiusitas dan entrepreneurship. Cognicia, 6, (1). $1-9$.

Entrepreneurship di sebagian besar negara berkembang merupakan penopang utama perekonomian. Entrepreneurship dapat menjadi roda penggerak ekonomi suatu negara dan menjadi roda perubahan suatu bangsa (Galbraith, 2007; Carswell and Rolland, 2007). Data entrepreneurship tahun 2017 (www.depkop.go.id) menunjukkan angka rasio wirausaha Indonesia saat ini adalah 3,1 persen. Artinya, dari 252 juta penduduk terdapat wirausahawan sebanyak 7,8 juta. Namun demikian, jumlah ini masih jauh lebih rendah dibandingkan dengan jumlah wirausahawan di beberapa negara tetangga, seperti Singapura (7\%), Malaysia (5\%), dan Jepang (11\%). Melihat kondisi ini, maka diperlukan berbagai strategi untuk meningkatkan kuantitas wirausahawan, khususnya di usia produktif (usia muda). Strategi dapat dilakukan sejak dini dengan bekerja sama pihak kampus atau lembaga pendidikan.

Dalam arti sederhana, entrepreneurship adalah kemampuan seseorang dalam berkreasi dan berinovasi untuk menciptakan dan mengembangkan sebuah produk dalam rangka memperoleh keuntungan (profit oriented). Ada tiga pendekatan yang dapat dilakukan dalam menganalisis entrepreneurship. Pertama, entrepreneurship dapat dijelaskan melalui pendekatan perilaku, yang menyatakan bahwa entrepreneurship adalah kemampuan untuk mendeteksi peluang, memotivasi dalam mencapai peluang, mengevaluasi, serta memanfaatkan kesempatan. Kedua yaitu pendekatan sikap, di 
mana entrepreneurship merupakan kemampuan seseorang dalam menempatkan posisi persaingan dalam menjalankan usahanya. Sedangkan yang ketiga adalah pendekatan proses, yang menyatakan bahwa entrepreneurship didasarkan pada proses yang mencerminkan upaya individu dalam mengidentifikasi sejumlah peluang dan menjelaskan sumber daya yang dibutuhkan untuk kegiatan bisnis (Lumpkin \& Dess, 1996).

Selain pentingnya kedudukan entrepreneurship dalam pengembangan dan kemajuan negara (Galbraith and Galbraith, 2007; Shakya, 2008), tema-tema entrepreneurship makin menarik untuk dibahas. Hal ini dikarenakan adanya kompleksitas dalam pembahasan entrepreneurship yang melibatkan tidak hanya ilmu ekonomi, melainkan lintas keilmuan seperti psikologi, sosial-humaniora, budaya, politik, dan keagamaan. Pembahasan entrepreneurship mendapatkan kompleksitasnya manakala semua komponen pembentuknya terlibat dan diurai dengan baik. Maka akan terlihat kontribusi masing-masing komponen dalam penyusunan model atau pengembangan konsep entrepreneurship. Peran entrepreneurship dalam mendorong berkembangnya perekonomian di Indonesia tidak diragukan lagi. Bahkan lembagalembaga pendidikan tinggi pun didorong untuk terus membenahi sistem agar mampu menciptakan lulusan dengan karakteristik yang siap menjadi seorang entrepreneur.

Pada awal perkembangan ilmu ekonomi, terdapat isu besar yang meyakini adanya posisi yang bersebelahan antara ekonomi dan agama. Agama memiliki ideologi metafisika (non materi) dan meminta pemeluknya menghindari urusan dunia, sedangkan ekonomi membicarakan fakta empirik dan perhitungan materi sehingga diyakini keberadaan agama akan melemahkan ekonomi. Namun Smith dan Weber berpendapat bahwa agama memainkan peran yang fundamental dalam membentuk ekonomi (Audretsch, Boente and Tamvada, 2007).

Religiusitas merupakan tingkat kepercayaan kepada Tuhan (keimanan) yang disertai dengan komitmen untuk mengikuti prinsip-prinsip yang diyakininya atas dasar agama tersebut. Dengan kata lain, religiusitas didefinisikan sebagai tingkat keyakinan yang spesifik dalam nilai-nilai agama dan cita-cita yang dipraktekkan oleh seseorang (McDaniel \& Burnett, 1990). Religiusitas berhubungan dengan pencapaian tujuan hidup dengan cara memaknai agama yang dianutnya melalui dimensi kognitif (pemahaman), afektif (pengalaman subyektif dalam beragama), dan perilaku (implikasi keyakinan dalam kehidupan sehari-hari) (Starck, 1983).

Tulisan ini akan memfokuskan hubungan religiusitas dengan entrepreneurship dengan alasan bahwa sebagian individu mempunyai sebuah keyakinan (belief) berkaitan dengan agama dan sangat memengaruhi pola pikir dan perilaku dalam kehidupan sehari-hari. Sementara entrepreneurship merupakan bagian dari perilaku ekonomi yang melekat dalam kehidupan seseorang, yang juga mencakup aspek value, sikap, dan perilaku tertentu, sehingga dibutuhkan sebuah tulisan yang dapat mengupas hubungan antara keduanya dengan tepat, luas, dan mendalam untuk memperoleh gambaran tentang posisi religiusitas dan entrepreneurship.

\section{METODE}


Penelusuran literatur dengan menggunakan database elektronik yang ada dalam Ebsco (http://search.ebscohost.com), ProQuest (http://search.proquest.com), dan Science Direct (http://www.sciencedirect.com) yang menyediakan artikel publikasi dalam berbagai disiplin ilmu, seperti ilmu kesehatan, psikologi, humaniora, sosial, teknik, dan agama. Indeks publikasi yang digunakan difokuskan pada ilmu psikologi untuk mendapatkan artikel publikasi dengan tema entrepreneurship dan religisitas.

Dari hasil penelusuran yang telah dilakukan, peneliti menetapkan beberapa artikel yang menenuhi kriteria, di antaranya (1) artikel tersebut membahas tentang entrepreneurship dan religiusitas, (2) artikel tersebut membahas tentang hubungan kedua variabel tersebut baik sebagai variabel bebas maupun variabel terikat, (3) artikel tersebut ditulis dalam bahasa Inggris, dan (4) artikel tersebut merupakan laporan hasil penelitian.

Literatur yang telah dikumpulkan sesuai dengan kriteria dianalisis untuk menemukan bukti adanya hubungan religiusitas dengan entrepreneurship melalui identifikasi, evaluasi, interpretasi dan diskusi untuk mendapatkan gambaran yang lebih nyata tentang hubungan antara religiusitas dan entrepreneurship serta memberikan penjelasan terhadap koneksitas antara keduanya.

\section{HASIL}

Hasil dari penelusuran literatur menemukan bukti sebagai berikut:

Noble at al (2007) menemukan adanya hubungan antara orientasi religusitas dengan aktivitas entrepreneurship (keadilan pasar) dan sifat entrepreneurship (pemberdayaan diri sendiri), di mana hubungan antara religiusitas dengan keadilan pasar ditentukan oleh orientasi religiusitasnya. Individu yang mempunyai orientasi internal dalam religiusitasnya cenderung curiga terhadap praktek keadilan pasar, sementara individu yang mempunyai orientasi eksternal cenderung menerima dan menganggap keadilan pasar lebih tinggi. Di samping itu, temuan Noble et al juga mengatakan bahwa kedua orientasi religiusitas berhubungan dengan sikap terhadap pemberdayaan diri. Orientasi internal lebih fokus pada motivasi diri dan harga diri, sementara orientasi eksternal cenderung fokus pada aktifitas entrepreneurship.

Carswell and Rolland (2007) menemukan bahwa religiusitas di New Zeland memengaruhi pertumbuhan ekonomi melalui kegiatan-kegiatan entrepreneurship. Penelitian di kalangan pemeluk agama kristen dan non kristen menunjukkan bahwa pemeluk non kristen menyukai kegiatan-kegiatan entrepreneurship dibandingkan pemeluk agama kristen. Penelitian juga menemukan bahwa keragaman agama memiliki pengaruh yang sangat kecil terhadap kontribusi entrepreneurship baik secara individual maupun komunitas.

Ferguson, Dougherty, \& Neubert (2014) menemukan bahwa agama ortodoks mempunyai hubungan negatif dengan pengambilan keputusan dalam perilaku entrepreneurship. Pemeluk ortodoks cenderung menghindari resiko dalam kehidupan, hal ini dikarenakan adanya sistem nilai tentang kepastian yang telah ditetapkan Tuhan dalam kitab suci dan cenderung melihat sesuatu yang kekal (tidak berubah), sehingga 
menghindari hal-hal yang tidak pasti. Kondisi ini bertolak belakang dengan sifat-sifat yang terkandung dalam entrepreneurship, yang membutuhkan kejelian dalam melihat situasi yang dianggap penuh ketidakpastian dan heterogen. Penelitian ini sejalan dengan temuan Nwankwo \& Gbadamosi (2013) yang menyatakan adanya hubungan antara religiusitas dengan nilai-nilai entrepreneurial.

\section{PEMBAHASAN}

Tulisan ini ingin menjelaskan entrepreneurship dengan mengembangkan konsep tersebut melalui perspektif religiusitas. Di samping itu, tulisan ini juga menawarkan alternatif perspektif bahwa religiusitas menjadi faktor-faktor yang dapat memengaruhi kinerja. Dalam konteks entrepreneurship, religiusitas akan memengaruhi sikap dan perilaku wirausahawan melalui penciptaan nilai, menjalankan kegiatan bisnis dengan lebih menekankan pada moral dan etika bisnis, karena agama pada dasarnya adalah sebuah sistem kepercayaan dan keyakinan yang berfungsi sebagai pedoman dalam menjalani hidup, salah satunya menekuni kegiatan bisnis. Penelitian-penelitian terkini mengenai hubungan agama dan entrepreneurship menunjukkan bahwa agama memengaruhi aktivitas entrepreneurship ( Galbraith \& Galbraith, 2007; Noble, Galbraith, Singh, \& Stiles, 2007; Valliere, 2008; Arief, 2013; Audretsch, Boente, \& Tamvada, 2007; Baharun \& Kamarudin, 2001; Balog, Baker, \& Walker, 2014; Dana, 2010). Pada saat ini, fenomena entrepreneurship tidak hanya dijelaskan melalui pendekatan psikologi dan sosial yang menekankan pada inovasi, penciptaan bisnis baru, pengembangan bisnis, dan sifat entrepreneurship. Penelitian-penelitian yang dilakukan sudah mengarah pada perspektif bahwa pengembangan entrepreneurship dapat diarahkan pada pendekatan agama (Antoncic \& Hisrich, 2003; Halis, Ozsabuncuoglu, \& Ozsagir, 2007), bahkan religiusitas telah menjadi isu penting dalam studi entrepreneurship dan manajemen.

Secara umum, religiusitas digambarkan sebagai seperangkat nilai-nilai, kepercayaan, norma, etika, dan perilaku yang harus dimiliki oleh seseorang dalam melaksanakan kegiatan usahanya. Beberapa studi telah memperkuat argumen bahwa nilai, kepercayaan, dan norma-norma akan memiliki dampak pada orientasi entrepreneurship (Adamu, Kedah, \& Osman-gani, 2011; Bergman \& Brodd, 2014; Busenitz, Gómez, \& Spencer, 2000). Dengan demikian, analisis perilaku entrepreneurship yang berdasarkan religiusitas memiliki manfaat besar untuk pencapaian keuntungan perusahaan menghadapi peningkatan kompleksitas antara pelanggan dan para pemegang saham.

Pengembangan konsep kewirausahaan dengan berdasarkan perspektif agama telah dikemukakan oleh beberapa penulis sebelumnya, seperti Antoncic dan Hisrich, (2003). Pendapat yang lain mengatakan bahwa keberhasilan entrepreneurship dalam meningkatkan kinerja sangat dipengaruhi oleh tingkat religiusitas wirausaha, dan religiusitas akan memiliki dampak pada sikap dan perilaku perbedaan dari wirausahawan (Carswell \& Rolland, 2007). Selain itu, religiusitas sebagai input dari budaya akan berperan dalam pengembangan entrepreneurship (Morrison, 2000). Individu dengan tingkat religiusitas yang baik akan selalu berusaha untuk menjalankan kegiatan bisnis dengan lebih menekankan pada etika, moralitas, dan peduli tentang lingkungan. Keyakinan dari individu akan mendorong mereka untuk 
menjadi seorang wirausaha (Audretsch, et. al, 2007), dan selanjutnya dengan keyakinan tersebut seseorang akan menjalankan aktivitas bisnis (Carswell dan Rolland, 2007). Studi empiris lain juga menjelaskan bahwa suatu bisnis yang dilakukan dengan dasar agama akan mampu mencapai kinerja yang superior (Iannaccone, 1998; Naughton \& Corwall, 2009).

Religiusitas akan memberikan dampak pada perilaku individu. Sebagai contoh, beberapa orang mungkin akan menggunakan pendekatan manajerial dalam melaksanakan kegiatan usaha, sementara yang lain akan menggunakan pendekatan keyakinan (Audretsch et al., 2007). Untuk masyarakat Muslim, perilaku entrepreneurship-nya selalu didasarkan pada Alquran dan hadis. Oleh karena itu, Islam memberikan cara yang berbeda untuk mendapatkan keuntungan dalam melayani Tuhan. Sudut pandang yang mungkin berbeda dengan tingkat perbedaan religiusitas akan memengaruhi cara seseorang menafsirkan kehidupan, dalam mengambil keputusan serta lebih sensitif terhadap kondisi lingkungan yang ada di sekitarnya (Dilmaghani, 2011)

Secara eksplisit, agama berkaitan dengan tingkat kepercayaan dan nilai-nilai yang dimiliki oleh seseorang dan sejauh mana mereka dapat menerapkan nilai-nilai dan keyakinan tersebut dalam kehidupannya. Dalam konteks kegiatan usaha, agama akan menentukan konsistensi dari perilaku yang ditunjukkan oleh orang yang menjalankan bisnis, seperti praktek bisnis yang memberikan prioritas kepada etika, kejujuran, dan terpercaya (Muhamad \& Mizerski, 2010). Konsep religiusitas dapat dilihat dari dua komponen, yaitu afiliasi keagamaan dan agamanya. Afiliasi keagamaan adalah sekelompok individu yang memiliki tujuan yang sama dengan religiusitas untuk memperkuat statusnya. Beberapa peneliti menduga bahwa afiliasi keagamaan berhubungan dengan sistem kognitif yang dimiliki oleh individu, yang digambarkan sebagai seperangkat keyakinan, nilai-nilai, harapan, dan perilaku yang akan didistribusikan kepada semua anggota dalam kelompok. Sistem kognitif juga berhubungan dengan spiritualisme yang menunjukkan tingkat individu dalam mempertahankan keyakinannya dan nilai-nilai kepercayaan (Muhamad \& Mizerski, 2010).

Religiusitas akan memengaruhi pilihan individu dalam melaksanakan aktivitas entrepreneurship (Audretsch et al., 2007). Selain itu, religiusitas akan bermanfaat untuk wirausaha dalam menghadapi perubahan lingkungan, sehingga akan mampu bertahan dalam lingkungan bisnis. Secara empiris, beberapa peneliti menyatakan bahwa religiusitas akan memberikan dampak pada pencapaian kinerja yang unggul (Kohl, 1984) dan keberhasilan entrepreneurship (Makhbul \& Hasun, 2011; Shariff \& Saud, 2009). Selanjutnya menjelaskan bahwa faktor-faktor yang mendorong keberhasilan entrepreneurship dalam menjalankan kegiatan bisnis melalui religiusitas dengan kemampuan mereka untuk membuat keputusan mereka sendiri dan kemampuan untuk mengendalikan organisasi memberikan kontribusi bagi keberhasilan mereka.

Meskipun demikian, masih sangat sedikit penelitian yang menggunakan pendekatan religiusitas dalam kaitannya dengan pencapaian kinerja perusahaan. Umumnya, beberapa peneliti mengembangkan konsep entrepreneurship dengan lebih 
menekankan pada entrepreneurship dalam sikap, perilaku, dan proses. Di satu sisi, perspektif religiusitas ini juga mampu menggambarkan tiga perspektif pengembangan konsep entrepreneurship. Beberapa penelitian telah dilakukan untuk menjelaskan sistem kepercayaan mampu menggambarkan bagaimana sikap yang harus ditunjukkan oleh seorang wirausaha, perilaku dan proses. Sebagai contoh, sebuah studi yang dilakukan oleh Iannaccone (1998); Audretsch, et al. (2013), menunjukkan bahwa religiusitas akan memengaruhi keputusan seseorang untuk menjadi entrepreneurship.

Untuk menjelaskan hubungan antara religiusitas dan sikap individu dan perilaku, kami menggunakan pendapat seperti yang diungkapkan oleh Dood (1998); Carswell dan Rolland (2007) bahwa religiusitas akan memengaruhi sikap dan perilaku wirausaha. Sikap dan perilaku individu dapat dilihat dari bagaimana mereka menjalankan kegiatan bisnis. Selain itu, sikap dan perilaku yang ditunjukkan dapat digunakan untuk mengidentifikasi peluang dan mengembangkan bisnis. Dalam pandangan kami, sikap dan perilaku yang ditunjukkan oleh religiusitas individu cenderung untuk menjalankan kegiatan usaha dengan lebih menekankan pada etika dan moral. Etika dalam menjalankan bisnis dan moralitas yang pada akhirnya akan membentuk nilai-nilai entrepreneurship.

Sementara beberapa peneliti menggunakan dimensi yang inovatif, proaktif, dan berani mengambil risiko untuk mengukur pencapaian kinerja entrepreneurship, maka ia dapat dijelaskan dengan perspektif yang berbeda dalam konsep religiusitas (Covin \& Slevin, 1991). Beberapa studi sebelumnya menyatakan bahwa ketika religiusitas individu mampu berperan sebagai faktor-faktor yang membedakan dengan individu yang lain, maka itu akan menimbulkan konsekuensi dari perbedaan dalam pencapaian kinerja. Sikap dan perilaku sebagai akibat dari religiusitas akan mendorong orang untuk bertindak dalam kinerja yang proaktif, inovatif, dan unggul sehingga dapat dicapai (Botsaris \& Vamvaka, 2012). Pencapaian kinerja yang unggul disebebkan karena adanya nilai yang dimiliki oleh seorang individu dalam melaksanakan kegiatan usaha. Dalam konteks ini, kinerja dapat dilihat dari pencapaian tingkat keuntungan, pangsa pasar, dan pertumbuhan atau kinerja non keuangan (Chandrakumara, De Zoysa, \& Manawaduge, 2011).

\section{SIMPULAN DAN IMPLIKASI}

Religiusitas sebagai sebuah keyakinan dan nilai-nilai hidup seseorang akan terimplikasi dalam pikiran, sikap dan perilaku sehari-hari. Religiusitas akan memengaruhi sebuah tatanan kehidupan seseorang, termasuk dalam perilaku ekonomi. Entrepreneurship merupakan salah satu kegiatan ekonomi untuk meningkatkan kesejahteraan hidup tidak dapat lepas dari pengaruh religiusitas yang dimiliki seseorang. Berbagai kajian dan penelitian telah memberikan bukti bahwa keberadaan religiusitas sangat memengaruhi karakteristik entrepreneurial, aktivitas entreprenerurship dan bahkan memengaruhi perkembangan ekonomi sebuah negara. Dengan demikian memperkuat dan mengkualitaskan religiusitas di tingkat individu maupun komunitas nakan memberikan dampak positif terhadap perkembangan entrepreneurship baik secara mikro (personal) maupun makro (negara).

\section{DAFTAR PUSTAKA}


Adamu, I. M., Kedah, Z., \& Osman-gani, A. (2011). Entrepreneurial Motivation, Performance and Commitment to Social Responsibility: A Conceptual Analysis on the Influence of Islamic Religiosity. In 10th International Conference of the Academy of HRD (pp. 1-33).

Ancok, D. (1994). Psikologi Islami: Solusi Islam Atas Problema-problema Psikologi. Jogjakarta: Pustaka Pelajar

Antoncic , B., \& Hisrich , Robert D. . (2003). Clarifying the intrapreneurship concept. Journal of Small Business and Enterprise Development, 10(1), 7-24.

Arief, M. (2013). A Theoretical Review of Entrepreneurship: The Effect of Religiosity to the Performance. International Conference on Entrepreneurship and Business Management (ICEBM 2013): Sanur, Bali - November 21-22, 2013, (November), 337-345.

Audretsch, D., Boente, W., \& Tamvada, J. (2007). Religion and entrepreneurship. Retrieved from http://papers.ssrn.com/sol3/papers.cfm?abstract_id=1136703

Baharun, R., \& Kamarudin, S. (2001). the Effects of Entrepreneurs' Personal Religious Values and Business Performance in Information Technology Industry. Journal of Enterprising Culture, 9(4), 437-448.

Balog, A. M., Baker, L. T., \& Walker, A. G. (2014). Religiosity and spirituality in entrepreneurship: a review and research agenda. Journal of Management, Spirituality \& Religion, 11(12), 159-186.

Bergman, J. B., \& Brodd, H. M. (2014). How National Values Influence Entrepreneurial Behaviour. ECTS.

Botsaris, C. A., \& Vamvaka, V. (2012). Models of the determinants of entrepreneurial behaviour: A literature review. Regional Science Inquiry Journal, 4(3 SPEC. ISSUE), 155-172.

Busenitz, L. W., Gómez, C., \& Spencer, J. W. (2000). Country institutional profiles: Unlocking entrepreneurial phenomena. Academy of Management Journal, 43(5), 994-1003.

Carswell, P., \& Rolland, Deborah. (2007). Religion and entrepreneurship in New Zealand. Journal of Enterprising Communities: People and Places in the Global Economy, $1(2), 162-174$.

Chandrakumara, A., De Zoysa, A., \& Manawaduge, A. (2011). Effects of the Entrepreneurial and Managerial Orientations of Owner-Managers on Company Performance: An Empirical Test in Sri Lanka. International Journal of Management, 28(1), 139-158.

Covin, J. G., \& Slevin, D. P. (1991). A Conceptual Model of Entrepreneurship as Firm Behavior. Entrepreneurship: Theory \& Practice, 16(1), 7-25.

Dilmaghani, M. (2011). Religiosity, human capital return and earnings in Canada. International Journal of Social Economics, 39(1/2), 55-80.

Dodd, S. D., \& Gotsis, G. (2007). An Examination of The interrelationships between entrepreneurship and religion. The International Journal of Entrepreneurship and Innovation, 8(2), 93-104. 
Dodd, S. D., \& Seaman, P. T. (1998). Religion and Enterprise: An Introductory Exploration. Entrepreneurship Theory and Practice, 71-87.

Downe-Wamboldt, B. (1992). Content analysis: Method, applications, and issues. Health Care for Women International, 13(3), 313-321.

Duygulu, E., \& Kurgun, O. A. (2009). The effect of managerial entrepreneurship behavior on employee satisfaction: Hospitality managers' dilemma. African Journal of Business Management, 3(11), 715-726.

Elo, S., \& Kyngäs, H. (2008). The qualitative content analysis process. Journal of Advanced Nursing, 62(1), 107-115.

Emami, M., \& Nazari, K. (2012). Entrepreneurship, Religion, and Business Ethics. Australian Journal of Business and Management Research, 1(11), 59-69.

Faizal, P. R. M., Ridhwan, A. A. M., \& Kalsom, A. W. (2013). The Entrepreneurs Characteristic from al-Quran and al-Hadis. International Journal of Trade, Economics and Finance, 4(4), 191-196.

Ferguson, Dougherty and Neubert (2014). Religious ortodoksy and entrepreneurial risk-taking. Sosiological Focus, 47 : 32 - 44. Copyright North Central Sociological Association. ISSN : 0038-0237 print / 2162-1128 online

Fitzsimmons, J., \& Douglas, E. J. (2005). Entrepreneurial Attitudes and Entrepreneurial Intentions : a Cross-Cultural Study of Potential Entrepreneurs in India , China , Thailand and Australia . Applied Optics, 47(June), 1-20. Retrieved from http://www.ncbi.nlm.nih.gov/pubmed/21198165

Galbraith, C. S., \& Galbraith, Devon M. (2007). An empirical note on entrepreneurial activity, intrinsic religiosity and economic growth. Journal of Enterprising Communities: People and Places in the Global Economy, 1(2), 188-201.

Gurol, Y. and Atsan, N. 2006. "Entrepreneurial characteristics amongs university students. Some insights for entrepreneurship education and training in Turkey," Education and Training, Vol. 48 (1), pp. 25-38.

Halis, M., Ozsabuncuoglu, I. H., \& Ozsagir, a. (2007). the Values of Entrepreneurship and Factors That Effect Entrepreneurship: Findings From Anatolia. Serbian Journal of Management, 2(1), 21-34.

Hill, J., \& Wright, L. T. (2000). Defining the Scope of Entrepreneurial Marketing: A Qualitative Approach. Journal of Enterprising Culture, 8(1), 23-46.

Iannaccone, L. R. (1998). Introduction to the Economics of Religion. Journal of Economic Literature, 36(3), 1465-1495.

Jong, E. De. (2008). Religious Values and Economic Growth : A review and assessment of recent studies. NiCE Working Paper 08-111, (November), 1-34.

Koh, H.C. 1996. "Testing hypotheses of entrepreneurial characteristics", Journal of Managerial Psychology, Vol. 11 (3), pp 12-25.

Kohl, J. P. (1984). Strategies for growth: Intervention in a church. Long Range Planning, 17(6), 76-81.

Lumpkin, G. T., \& Dess, G. G. (1996). Clarifying the entrepreneurial orientationconstruct and linking it to performance. Academy of Management Review, 21(1), 135-172.

Makhbul, Z. M., \& Hasun, F. M. (2011). Entrepreneurial Success : An Exploratory Study among Entrepreneurs. International Business and Management, 6(1), 116-125. 
McCleary, R. M., \& Barro, R. J. (2006). Religion and Economy. Journal of Economic Perspectives, 20(2), 49-72.

McDaniel, S. W., \& Burnett, J. J. (1990). Consumer religiosity and retail store evaluative criteria. Journal of the Academy of Marketing Science, 18(2), 101- 112.

Morris, M. H., Lewis, P. S., \& Sexton, D. L. (1994). Reconceptualizing entrepreneurship: An Input-Output Perspective. SAM Advanced Management Journal, 59(1), 2131.

Morrison, A. (2000). Entrepreneurship: what triggers it? International Journal of Entrepreneurial Behavior \& Research, 6(2), 59-71.

Muhamad, N., \& Mizerski, D. (2010). The constructs mediating religions' influence on buyers and consumers. Journal of Islamic Marketing, 1(2), 124- 135.

Naughton, M., \& Cornwall, J. R. (2009). Culture as the Basis of The Good Entrepreneur. Journal of Religion \& Business Ethics, 1(1), 1-13.

Noble, A. De, Galbraith, Craig S., Singh, Gangaram, \& Stiles, Curt H. (2007). Market justice, religious orientation, and entrepreneurial attitudes: An empirical study. Journal of Enterprising Communities: People and Places in the Global Economy,1(2),121-134.

Nwanko S and Gbadamosi, A (2013). Faith and entrepreneurship among the british african-caribbean : intersections between religious and entrepreneurial values. Journal of Small Bussiness and Enterprise Development. Vol. 20 No. 3, 2013 pp. 618-633

Patel, M. (2003). Influence of Religion on Shopping Behaviour of Consumers-an Exploratory Study. Journal of Research in Commerce \& Management, 1(5), 6878.

Shakya, Mallika (2008). Cultural Capital amd Entrepreneurship in Nepal : The Readymade Garment Industry as a Case Study.UMI. Proquest LLC.

Valliere, D. (2008). Exploring Buddhist influence on the entrepreneurial decision. International Journal of Entrepreneurial Behaviour \& Research, 14(3), 172- 191. 